\title{
Determining the impact of lecture videos on student outcomes
}

\author{
Barbara Robertson and Mark J. Flowers
}

\begin{abstract}
The course materials students are expected to utilise in online instruction vary. Studies have shown that students tend to enjoy online courses with lecture videos more than those without, but few studies have measured the impact of lecture videos on student outcomes. Do lecture videos increase student understanding and retention, thus improving student outcomes? Students were provided with one or more study aids, video lecture, PowerPoint or instructor-created notes for learning about the role of the Electoral College in US presidential elections. We assessed student retention and understanding of the Electoral College with a quiz as an indicator of student outcomes. We found that the video lecture in combination with a PowerPoint was the most effective study aid.
\end{abstract}

\section{KEYWORDS \\ distance education, higher education, instructional technology, lecture capture, online teaching, student outcomes, student performance, video lecture}

Use of online courses in bricks-and-mortar colleges and universities has increased substantially, as have the number of traditional and non-traditional students seeking to take courses online. ${ }^{1}$ The course materials online students are expected to use vary greatly. Some instructors go to great lengths to create custom content, such as detailed PowerPoints or lecture videos, while others rely on master course templates shared among faculty in the discipline and often supplied by textbook publishers. Without becoming synchronous, the online classroom may more closely resemble the traditional in-class experience, while retaining the ability of students to fit their studies into their schedules and juggle additional responsibilities, especially through the availability of lecture videos. Face-to-face instruction in classrooms can 
be supplemented by video lectures as well, allowing students who have missed class or those needing additional time with the lesson to access the same level of classroom instruction outside of the classroom.

This study investigates the impact of lecture videos on student outcomes. Lecture capture technology ${ }^{2}$ was used to produce the videos for multiple online and face-to-face sections of an 'Introduction to American Government' course across six semesters (Fall, Spring and Summer) and students were given access to several combinations of lecture resources designed to teach about the Electoral College. Students were then required to complete an assessment in the form of a twelve-question quiz about the Electoral College, and afterwards to complete a survey designed to evaluate how much of the lecture materials provided were used. Each student had access to a minimum of the course textbook and instructor-created PowerPoint lecture slides. Some course sections were given the PowerPoint with detailed notes also included. Others were given a PowerPoint with detailed notes and a lecture video about the Electoral College, while some were given the lecture video and PowerPoint, but without the detailed notes included.

This study accounted for the usage of the textbook, but primarily explored the use of lecture videos, PowerPoint, and instructor-created notes on an assessment to see if some combination was better or worse when it comes to understanding and retention. To determine which students self-selected into which combination of resources or treatment, a post quiz survey was administered to the participants.

Participation in this study was voluntary. The students who agreed to participate consented to the use of their survey responses, quiz grade and final course grade in the study. No information identifying any student was shared beyond the principal investigator. This study was approved by the Institutional Review Board (IRB) at Georgia State University prior to implementation.

\section{Review of the literature}

The literature on the use of lecture capture suggests numerous advantages. First, there is strong evidence to suggest that at a minimum, students enrolled in online classes and face-to-face classes feel greater satisfaction with courses where lecture videos are provided online. Greater student satisfaction has been found in face-to-face courses in which instructors provided lecture capture videos in the learning management system as a supplement to the traditional lecture already given (Bollmeier et al. 2010; Bryans Bongey et al. 
2006; Choi and Johnson 2005; Cramer et al. 2007; Evans 2014; Maag 2004; Rogers and Cordell 2011; Rose 2009; Vajoczki et al. 2010; Whatley and Ahmad 2007; Zhang et al. 2006). This may be partly attributable to the individualised learning that lecture capture allows for. Both face-to-face and online students, whether viewing a lecture video for the first time or for review, can pause, rewind or repeat the lecture. Among other benefits, this allows the student to review for an exam and to revisit topics they are struggling with for deeper understanding and increased retention (Copley 2007; Gorissen et al. 2012; Gosper et al. 2010; Traphagan et al. 2010; Zhang et al. 2006). Additionally, the availability of lecture videos enables students in both types of classroom settings to generate more comprehensive notes. Students from the face-toface class who either missed a class or feel that there are gaps in their notes may watch a lecture video in their own time and create more comprehensive and detailed notes for study. Online students can generate notes from the explanations and examples of concepts given by the instructor in the video (Brotherton and Abowd 2004; Luna and Cullen 2011). To date there has been no evidence to suggest that the availability of lecture videos for face-to-face classes has a negative impact on student attendance (Bollmeier et al. 2010; Brotherton and Abowd 2004; Bryans Bongey et al. 2006; Copley 2007; Davis et al. 2009; Toppin 2011; Wiese and Newton 2013).

Lecture videos make a course and its content more accessible to students with disabilities or students with English as a second language. Whether offered in a traditional face-to-face class or in an online section, the availability of lecture videos better enable students with disabilities or students for whom English is not a first language to overcome their individual challenges (Scutter et al. 2010). Additionally, lecture videos reduce requests to instructors for content clarification. Traditional classroom students can access lectures outside of class and revisit a topic they are struggling to comprehend. This 'second look' at the concept may generate a better understanding and thus negate the need to contact the instructor via phone or email (Holbrook and Dupont 2009; Rogers and Cordell 2011; Vajoczki et al. 2011). For online students, the lecture video may offer greater clarification of difficult concepts than the textbook or PowerPoint slides, thus reducing the need to contact the instructor for clarification in the online class as well.

Research has shown that after using lecture videos students tend to feel they have an enhanced understanding of content, and some studies have indicated better learning outcomes as evidenced by improved grades (Bollmeier et al. 2010; Francom et al. 2011; Harrigan 1995; Sloan and Lewis 2014; 
Vajoczki et al. 2010; Wiese and Newton 2013). Multiple studies have shown that students believe lecture videos will increase their overall understanding of content and help them recall more of the information presented (Bryans Bongey et al. 2006; Hartsell and Yuen 2006; Holbrook and Dupont 2009; Luna and Cullen 2011; Vajoczki et al. 2011). Moreover, previous research suggests that the utilisation of multiple senses is beneficial to learning, primarily because students find learning more enjoyable and tend to retain more information for longer. By watching lecture videos, students are not just reading to learn, but simultaneously seeing and hearing words, images and explanations, thus enhancing retention (Graber 1990; Hughes 2009; Mayer 2009).

Still, there has not been enough research on the question of whether students are indeed performing at higher levels as a result of viewing lecture videos or if there are other variables at play. Of the few studies seeking to measure the impact of video usage on learning outcomes, most are set in the context of the traditional classroom, exploring the impact of lecture capture video as a supplemental tool or in place of a missed class. In those studies, researchers found that viewing lecture capture videos in place of or in addition to live lectures was positively correlated with higher outcomes after controlling for the academic abilities of students using GPA as the proxy (Bollmeier et al. 2010; Francom et al. 2011; Harrigan 1995; Vajoczki et al. 2010; Wiese and Newton 2013). Very little research has sought to measure the impact of lecture videos strictly in the online learning environment when there is not a live lecture for which a video may serve as a supplement, and even fewer have explored combinations of study aids (Evans 2014). Heather Evans (2014) researched whether recorded lectures were superior to still slides by giving one online section PowerPoint with lecture notes all semester and giving videos only to another online section of an equal number of students. In the videos, the instructor can be seen lecturing over the same PowerPoint given to the PowerPoint-only class section. That study found course grades were lower for the video class than for the PowerPoint class. However, the total number of observations did not exceed sixty students and observations were limited to one semester.

To summarise so far, studies have shown that students tend to express greater satisfaction with courses that provide video lectures. Literature concerning the use of lecture videos supports numerous advantages to students who receive and instructors who provide lessons in an audio/visual format. Few studies, however, have measured the impact of lecture videos on student outcomes. Fewer still explore the videos with or without a combination of 
other lesson resources such as the course textbook or written instructional materials like PowerPoints or lecture notes. Furthermore, most studies also rely on a relatively small number of observations, in online only course sections, and do not directly test the impact of lecture resources on student outcomes for a single topic. Previous research attempting to measure the impact of lecture resources do not sufficiently indicate, measure or verify the extent of the student's use of lecture resources, especially lecture videos or other course materials such as the textbook and PowerPoints, and few if any restrict their question to a single lesson. Researchers have assumed if a student clicked a link, the student then used or studied the resource's content, although Thomas Sloan and David Lewis acknowledge the limits of this method of verification (2014).

The use of study aids by students must be verified before drawing conclusions about the impact of the aid on the student's performance. Furthermore, class sections normally tend not to be distributed by themselves. A wider cross-section of students is necessary to draw such conclusions, which we provide. We follow up on Heather Evans and Victoria Cordova's (2015) suggestion to evaluate lecture videos and still slides to improve student educational outcomes and confirm student use or disuse of the aids provided. Addressing some other concerns raised in the previous paragraph, we also limited our study to only one topic and explored both face-to-face and online students. We also did not assume student opinions were sufficient for establishing whether or not a method was viable. Recently Khe Foon Hew and Chung Kwan Lo (2018), for example, evaluated six different video types for impact on student learning. However, their study was very small, with only twenty-four observations, focused heavily on student preference, and did not evaluate student outcomes for video PowerPoints with narration after it was indicated as not preferred by the students. With such a small sample, ruling out any treatments seems arbitrary, thus we evaluated student outcomes for the group not tested.

We conducted a relatively large study, with 436 observations across multiple online and face-to-face sections, and we conclude that the inclusion of additional aids with video and narration is more effective than PowerPoint alone. Illa Mudasih and Waspodo Subroto (2019) explored a similar question, and drew a similar conclusion, but they left out other combinations of study aids that we have included - primarily, instructor-provided notes and a textbook. Additionally, most of the studies above did not consider student type, ${ }^{3}$ which we included. While these papers provide confidence that we can accept our hypothesis that video with PowerPoint improves student 
outcomes, all the above studies have fewer observations and leave out other important considerations that we include.

\section{Research design}

Involving 436 students, this study tests the hypothesis that students who use a lecture video in addition to other study aids, such as a PowerPoint, instructor-provided notes or a textbook, will achieve higher quiz grades than students who used PowerPoint alone. The dependent variable in this study was the student's quiz grade for a twelve-question, fifteen-minute timed quiz about the Electoral College. Students did not have access to the quiz questions prior to starting the quiz and were only given one attempt. We conducted the experiment on multiple face-to-face and online course sections of an 'Introduction to American Government' course over a two-year time period at a two-year college. The primary independent variables were:

1. Forty-five-minute lecture video

2. PowerPoint presentation provided by the instructor

3. Instructor-created notes provided to the student within the PowerPoint presentation

The instructor randomly assigned different treatments to course sections each semester for two years. Every student was instructed to refer to the pages in the course textbook that pertained to the Electoral College and an instructor created PowerPoint for that lesson. The treatments assigned were then varied by what additional resources the students were provided or self-selected into. Some course sections were restricted to only the textbook and PowerPoint slides, while other sections could use the textbook and PowerPoint slides with instructor-created lecture notes included. The notes included explanations and elaborations that the instructor would otherwise have made during a live or recorded lecture. The remaining sections were given a lecture video in addition to the PowerPoint, some with and some without instructor-created notes. Table 1 lists and summarises the various treatments. Whether given notes in addition to the slides or not, all students who received the video were encouraged to print or download the PowerPoint in advance of watching the video in order to take their own notes.

Because they do not always use the resources instructors recommend or make available, some students then self-selected into a different treatment 
Table 1. Variables and Type

\begin{tabular}{l|c|c}
\hline & Variable Type & $\begin{array}{c}\text { Count of } \\
\text { "Yes" Indicator }\end{array}$ \\
\hline Students Final Grade in the Course & Continuous & N/A (436 obs) \\
\hline $\begin{array}{l}\text { Course Textbook References to } \\
\text { the Electoral College }\end{array}$ & Binary & 207 \\
\hline Instruction (Face-to-Face $=1$ ) & Binary & 292 \\
\hline Video, PowerPoint, \& Notes & Binary & 49 \\
\hline Video \& PowerPoint (No Notes) & Binary & 124 \\
\hline PowerPoint \& Notes (No Video) & Binary & 121 \\
\hline Video (No PowerPoint, No Notes) & Binary & 95 \\
\hline PowerPoint (No Video, No Notes) & $\begin{array}{c}\text { Binary } \\
\text { (omitted) }\end{array}$ & 31 \\
\hline $\begin{array}{l}\text { No Study Aids Used } \\
\text { (No Video, PowerPoint, or Notes) }\end{array}$ & Binary & 16 \\
\hline
\end{tabular}

by foregoing a resource. If the student did not use the lecture video despite it being made available to them, they were not included in the sample of video students. To verify their treatment, each student was asked to complete a survey after taking the quiz. Each student was asked to indicate their level of use of each of the study aids available. Students were only considered to be in the video treatment groups if they indicated in the survey that they watched over 50 per cent of the video. Students were also able to indicate whether they used the course textbook, PowerPoint slides and PowerPoint notes to prepare for the quiz. This study does not seek to determine and analyse the extent of notetaking done by the students. While not perfect, the survey is a reliable method of measuring the student's engagement with the lecture video or other resources.

\section{Methods}

To evaluate the effectiveness of each treatment combination on quiz grade, we used the best, linear, unbiased estimator to fit a model with minimised errors. ${ }^{4}$ The unit of analysis for this experiment was student quiz grade, and 
we applied several different treatments, attempting to account for various study aids provided to the students. Since all students were provided at least PowerPoint slides, we measured our various treatment affects against those students who only received PowerPoint slides and no other treatments. For the experiment, we included a treatment for students receiving all study aids, including video lecture, PowerPoint slides, and instructor-provided notes. We also included a treatment where students received the video lecture and PowerPoint but without notes. Finally, we included a treatment for students who were provided no video lecture but did get the PowerPoint slides and instructor notes. For our control group, we provided students with only the PowerPoint slides but no notes or video.

Since we could only provide and strongly encourage the use of the study aids, students could opt out of their assigned treatment group by simply ignoring the provided materials. So, in addition to the above variables, we included variables to account for students who had access to their treatment group's treatment variables but took advantage of fewer than all the available study aids provided. We used information from the post-quiz survey to compile these remaining variables. The additional variables included video lecture only and no use of any of the provided study aids. Finally, we explored the effect of the use of the textbook across all groups. Students were not restricted from using their textbook in any group, but not all students used it.

The potential for some students to opt out of using the study aids provided also introduced some concern for selection bias in the model. To account for this concern, we used the student's final semester grade in the overall regression as a proxy for student type, student pre-existing knowledge, interest, and study habits. Students who were inclined to perform better overall in the course were more likely to earn higher scores on the quiz, just as those who do not typically study were less likely to use the materials provided. The final semester grade is not a perfect proxy, as it includes the quiz grade. Since the quiz grade was a relatively small portion of the final grade, only about 5 per cent, we were not concerned it would significantly alter our conclusions or introduce any problems of variables moving together or being jointly related, a problem known as multicollinearity.

\section{Results and analysis}

We set our level of statistical significance at 95 percent a priori, and to meet similar and generally accepted levels within the existing literature. Observ- 
ing Figure 1, where the vertical line indicates the use of PowerPoint alone, we can see students who used video with PowerPoint and notes earned a grade 6.48 percentage points higher than students who used PowerPoint alone. Students who used video with PowerPoint but no instructor-provided notes earned 5 percentage points higher than students who used PowerPoint alone. Not surprisingly, our proxy for student performance also proved to be statistically significant, but the coefficient was relatively small at 0.43 , so the effect on the quiz was not very interesting. Instruction type, online versus face-to-face, was not statistically significant, so we could not conclude that any difference in the quiz grade resulted from how the course was being taught. Video only was also not statistically significant; thus, we could not determine an effect from video alone when compared to PowerPoint alone. Finally, of the students who used no study aids, there was no statistical significance, thus we could not conclude any difference in outcomes between no aids and PowerPoint alone.

The use of textbooks was significant and very interesting. At first glance the negative coefficient indicates a surprising result from the effect of using a textbook; however, on further examination we think the reason is logical.

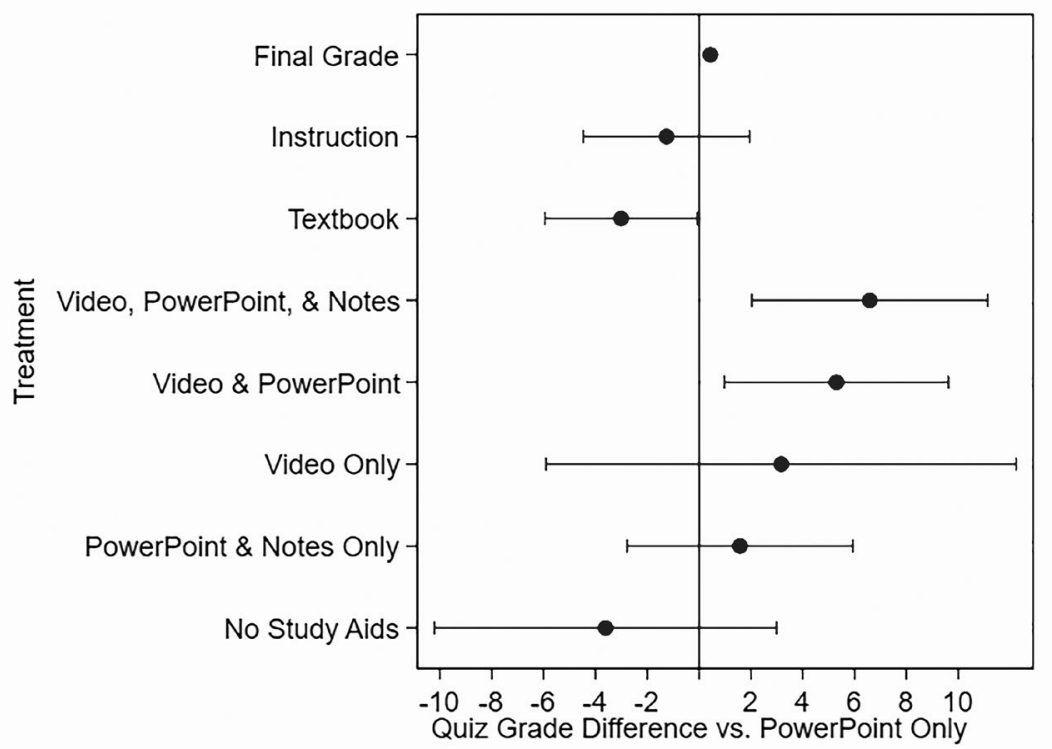

Figure 1. Effect of treatment on quiz grade 
It appears what we are observing is that no matter what treatment group a student was assigned, those who did not understand the material for the quiz then reverted to using their textbook. Their last-minute attempt to find content in order to answer questions is indicative of a lack of student preparation for the quiz, thus we see a negative effect from students using their textbook.

Table 2. Effect of treatment on quiz grade

\begin{tabular}{|c|c|c|}
\hline DV = Quiz Grade & Coefficients* & $\mathrm{p}$-value \\
\hline \multirow[t]{2}{*}{ Final Grade } & 0.434 & 0.000 \\
\hline & $(0.060)$ & \\
\hline \multirow[t]{2}{*}{ Textbook } & -3.013 & 0.044 \\
\hline & $(1.495)$ & \\
\hline \multirow[t]{2}{*}{ Instruction Type } & -1.257 & 0.442 \\
\hline & $(1.635)$ & \\
\hline \multirow[t]{2}{*}{ Video, PowerPoint, \& Notes } & 6.588 & 0.005 \\
\hline & $(2.315)$ & \\
\hline \multirow[t]{2}{*}{ Video \& PowerPoint } & 5.299 & 0.016 \\
\hline & $(2.200)$ & \\
\hline \multirow[t]{2}{*}{ PowerPoint \& Notes Only } & 1.577 & 0.477 \\
\hline & $(2.215)$ & \\
\hline \multirow[t]{2}{*}{ Video Only } & 3.167 & 0.493 \\
\hline & $(4.616)$ & \\
\hline PowerPoint Only & \multicolumn{2}{|c|}{ (Omitted) } \\
\hline \multirow[t]{2}{*}{ No Study Aids Used } & -3.610 & 0.283 \\
\hline & (3.359) & \\
\hline \multirow[t]{2}{*}{ Constant } & 48.686 & 0.000 \\
\hline & $(4.930)$ & \\
\hline $\mathrm{N}$ & 436 & \\
\hline $\mathrm{R}^{2}$ & 0.238 & \\
\hline$\sqrt{\mathrm{MSE}}$ & 15.227 & \\
\hline
\end{tabular}

* Robust Standard Error in Parenthesis 
Therefore, we conclude that it was not the use of the textbook that caused students to experience a decreased grade. We think we are seeing that students struggling to understand the content perhaps due to a lack of engagement with the provided study aid(s), reverted to their textbook as a resource, either before or after beginning the quiz. Indeed, more than 60 per cent of the students who reverted to their textbook opted not to use one or more of the study aids provided, with an overwhelming majority of that group not using the video lecture and at least one of either PowerPoint or instructor notes. Given that reasoning, we cannot determine that the use of the textbook caused a negative effect on any student's grade, but we can reason that those students who used the textbook were probably already struggling.

Given the results of the experiment, we think it is safe to conclude that the video lecture was statistically significant and improved student outcomes. When combined with the PowerPoint and instructor-provided lecture notes, student outcomes are even better. Finally, we see no statistically significant evidence that PowerPoint slides provided with instructor notes influence our students' outcomes. While other aids seemed necessary, it was the combination of aids with a video that gave the best student outcomes.

\section{Conclusion}

Previous research has shown that students tend to be happier with both face-to-face and online courses that provide lecture videos. With regards to student outcomes, previous scholarship has also concluded that students tend to understand and retain more when multiple senses are used to learn a subject. The use of videos in addition to written materials allows the student to read, see, and hear words, images and explanations. We report that students who used the combination of the lecture video and PowerPoint had higher outcomes on the quiz than students who did not.

We find that the combination of course materials is important since neither PowerPoint with notes nor video alone were significantly different from PowerPoint alone. Therefore, we conclude that student outcomes are higher when written materials (PowerPoints, handouts, lecture notes) are supplemented with video, and that video is better when supplemented with other written materials. Therefore, we suggest providing a written resource for students to aid in note taking or understanding and review in addition to a video aid. Since students with access to video(s) and written materials perform better on assessments, we surmise that the creation of video lectures 
is meaningful and worth the time, but only when provided with other, traditional materials as well.

In conclusion, we offer a few suggestions for future research and for those seeking to create or offer lecture videos as part of their course content. First, lecture videos are more dynamic when instructors do not simply read a list of bullet points from a slide. Similar to the face-to-face classroom setting, in a video the instructor can elaborate, explain and provide examples while prompting students to take notes and referring to the PowerPoint slides provided. The video with the PowerPoint slides enables the students to go back to the video for further clarification and spark their memory when reading their notes. Moreover, to better engage students with content, instructors can use the animation features in PowerPoint to restrict what a viewer sees within an individual slide. That restriction prevents students from advancing faster than the instructor but allowing them access to the PowerPoint also helps them make connections while watching the video as they anticipate what is coming next. Images (pictures, tables, etc.) and animations such as arrows and smart art charts can also be included in the slideshow and recorded onto the video for better clarification.

We would like to further explore this project by investigating whether open captions displaying what is spoken as text would be better or worse for retention than a narrated PowerPoint with notes and/or a transcript. Additionally, the length of the video may make a difference in student retention. Longer videos, such as the forty-five-minute video used in this study, may not be optimal for student attention spans or content absorption. However, the long video is a good comparison with face-to-face lectures that are typically between forty-five and seventy minutes. In both instances, instructors hope students take good notes and review them while seeking out additional resources to ensure comprehension and retention. Multiple, shorter videos over one course topic or chapter may be cumbersome for some courses, but they may be more effective for student retention and better enable students to watch them when convenient. Furthermore, shorter videos may be more efficient when course content must be updated or edited when subject matter evolves quickly.

Future research may also seek to more directly test the effects of video lectures over several topics within a section, ideally across multiple lessons and assessments. Additionally, more research may need to be done to study the effects of the talking head method, a lecture capture that includes the instructor on the screen and indicated as preferred by students in the Hew 
and Lo (2018) study. We conclude that lecture notes and PowerPoints in addition to a video do improve student outcomes, but more research is necessary to explore the best applications to maximise this result.

Barbara Robertson is Lecturer in Political Science at Georgia State University's Perimeter College. She holds a Master's in Political Science and is a recipient of the Governor of Georgia's Teaching Fellowship. Her academic interests include democratisation and democratic erosion, authoritarianism, American government and politics, American history, international politics and Middle Eastern politics and history, as well as the scholarship of teaching and learning.

Email: brobertson@gsu.edu

Mark J. Flowers is the Associate Chair of Business and Social Science at the Decatur campus for Georgia State University's Perimeter College, an Assistant Professor of Economics and former Fellow of the Virtual Fellows Program of the United States Department of State. Mr. Flowers' research interests are in Economic Development and International Relations where he focuses on the division of trust and influence among states and how states develop and execute their foreign policy agendas. Email: mflowers@gsu.edu

\section{Notes}

1. Traditional students tend to begin college shortly before or after earning a high school diploma, are enrolled full-time, and do not work or only work part-time. Non-traditional students have typically been out of college for a period of time, may have children and/or work part- or full-time jobs that may make full-time enrolment in college difficult or impossible.

2. Lecture capture technology records the instructor's voice with text, images and video clips displayed on a computer screen. It may be accomplished by recording the instructor in the classroom using a traditional video camera but is more commonly done through screencasting. Screencasting allows an instructor to simultaneously record audio and content displayed on the computer screen, something not easily done with a traditional video camera. It can be done by the instructor in a home or office setting using a personal computer or in a live classroom. For example, an instructor may narrate over a PowerPoint, with the additional ability to navigate to web pages or other digital resources during narration. 
3. Student type was measured using the final semester grade for each student. We assumed higher grades probably indicated more studious students and lower grades probably indicated less studious students. The assessment for the dependent variable of this study was a very small, although important, portion of the overall course grade.

4. We used Ordinary Least Squares to estimate the line of best fit across the multiple dimensions of this analysis. OLS is the best, linear, unbiased estimator that meets the Gauss-Markov assumptions. A Breusch-Pagan test indicated the data was heteroskedastic, that is, varied unevenly across the sample, so we corrected for the problem by using robust standard errors.

\section{References}

Bollmeier, S., P. Wenger and A. Forinash (2010), 'Impact of online lecture capture on student outcomes in a therapeutics course', American Journal of Pharmaceutical Education 74, no. 7: 1-6. https://www.ncbi.nlm.nih.gov/pmc/articles/PMC2972522/.

Brotherton, J., and G. Abowd (2004), 'Lessons learned from eClass: Assessing automated capture and access in the classroom', ACM Transactions on Computer-Human Interaction 11, no. 2: 121-155. https://doi.org/10.1145/1005361.1005362.

Bryans Bongey, S., G. Cizadlo and L. Kalnbach (2006), 'Explorations in course-casting: podcasts in higher education', Campus-Wide Information Systems 23, no. 5: 350-367. https://doi.org/10.1108/10650740610714107.

Choi, H., and S. Johnson (2005), 'The effect of context-based video instruction on learning and motivation in online courses', The American Journal of Distance Education 19, no. 4: 215-227. https://doi.org/10.1207/s15389286ajde1904_3.

Copley, J. (2007), 'Audio and video podcasts of lectures for campus-based students: production and evaluation of student use', Innovations in Education and Teaching International 44, no. 4: 387-399. https://doi.org/10.1080/14703290701602805.

Cramer, K. M., K. R. Collins, D. Snider and G. Fawcett (2007), 'The virtual lecture hall: Utilisation, effectiveness and student perceptions', British Journal of Educational Technology 38, no. 1: 106-115. https://doi.org/10.1111/j.1467-8535.2006.00598.x.

Davis, S., A. Connolly and E. Linfield (2009), 'Lecture capture: Making the most of faceto-face learning', Engineering Education 4, no. 2: 4-13. https://doi.org/10.11120/ ened.2009.04020004.

Evans, H. K. (2014), 'An experimental investigation of videotaped lectures in online courses', TechTrends 58, no. 3: 63-70. https://doi.org/10.1080/15512169.2015.1069198.

Evans, H. K. and V. Cordova (2015), 'Lecture videos in online courses: A follow-up', Journal of Political Science Education 11, no. 4: 472-482. https://doi.org/10.1080/ 15512169.2015.1069198.

Francom, J., T. G. Ryan and M. Kariuki (2011), 'Effects of podcasting on college student achievement and attitude', Journal of the Research Center for Educational Technology 7, no. 1: 39-53. 
Gorissen, P., J. Bruggen and W. Jochems (2012), 'Students and recorded lectures: Survey on current use and demands for higher education', Research in Learning Technology 20, no. 3: 297-311. http://dx.doi.org/10.3402/rlt.v20i0.17299.

Gosper, M., M. McNeill, R. Phillips, G. Preston, K. Woo and D. Green (2010), 'Web-based lecture technologies and learning and teaching: A study of change in four Australian universities', Research in Learning Technology 18, no. 3: 251-263. https://doi.org/ 10.1080/09687769.2010.529111.

Graber, D. (1990), 'Seeing is remembering: How visuals contribute to learning from television news', Journal of Communication 40, no. 3: 134-156. https://doi.org/ 10.1111/j.1460-2466.1990.tb02275.x.

Harrigan, K. (1995), 'Self-paced education with compressed interactive audio learning', Journal of Research and Computing Education 27, no. 3: 361-370. https://doi.org/ 10.1080/08886504.1995.10782138.

Hartsell, T., and S. C. Y. Yuen (2006), 'Video streaming in online learning', AACE Journal 14: no. 1: 31-43. https://doi.org/10.1080/08886504.1995.10782138.

Hew, K. F. and C. K. Lo (2018), 'Comparing video styles and study strategies during video-recorded lectures: Effects on secondary school mathematics students' preference and learning', Interactive Learning Environments. https://doi.org/10.1080/ 10494820.2018.1545671.

Holbrook, J. and C. Dupont (2009), 'Profcasts and class attendance - does year in program matter?', Bioscience Education 13, no. 1: 1-4. https://doi.org/10.3108/beej.13.c2.

Hughes, G. D. (2009), 'Using videos to bring lecture to the online classroom', College Quarterly 12, no.1. https://files.eric.ed.gov/fulltext/EJ864472.pdf.

Luna, G., and D. Cullen (2011), 'Podcasting as complement to graduate teaching: Does it accommodate adult learning theories?', International Journal of Teaching and Learning in Higher Education 23, no. 1: 40-47. https://files.eric.ed.gov/fulltext/EJ938577.pdf.

Maag, M. (2004), 'The effectiveness of an interactive multimedia learning tool on nursing students' math knowledge and self-efficacy', Computers, Informatics, Nursing 22, no. 1: 26-33. https://repository.usfca.edu/cgi/viewcontent . cgi? article $=1012 \&$ context $=$ nursing_fac.

Mayer, R. (2009), Multimedia Learning (Cambridge: Cambridge University Press). https:// doi.org/10.1017/СBO9780511811678.

Mudasih, I. and W. T. Subroto (2019), 'Comparison of student learning outcomes through video learning media with Powerpoint', International Journal of Educational Research Review 4, no. 2: 183-189. https://doi.org/10.24331/ijere.517997.

Rogers, R., and S. Cordell (2011), 'An examination of higher education students' opinions of the lecture capture system Tegrity', Journal of Technology Integration in the Classroom, 3, no. 1: 75-90. http://dx.doi.org/10.5206/cjsotl-rcacea.2016.1.8.

Rose, K. (2009), 'Student perceptions of the use of instructor-made videos in online and face-to-face classes', Journal of Online Learning and Teaching 5, no. 3. https:// jolt.merlot.org/vol5no3/rose_0909.htm. 
Scutter, S., I. Stupans, T. Sawyer and S. King (2010), 'How do students use podcasts to support learning?', Australasian Journal of Educational Technology 26, no. 2: 180-191. https://doi.org/10.14742/ajet.1089.

Sloan, T. and D. Lewis (2014), 'Lecture capture technology and student performance in an operations management course', Decision Sciences Journal of Innovative Education 12, no. 4: 339-355. https://doi.org/10.1111/dsji.12041.

Toppin, I. (2011), 'Video lecture capture (VLC) system: A comparison of student versus faculty perceptions', Education and Information Technologies 16, no. 4: 383-393. https://doi.org/10.1007/s10639-010-9140-х.

Traphagan, T., J. Kucsera and K. Kishi (2010), 'Impact of class lecture webcasting on attendance and learning', Educational Technology Research and Development 58, no. 1: 19-37. http://dx.doi.org/10.1007/s11423-009-9128-7.

Vajoczki, S., S. Watt, N. Marquis and K. Holshausen (2010), 'Podcasts: Are they an effective tool to enhance student learning? A case study from McMaster University, Hamilton Canada', Journal of Educational Multimedia and Hypermedia 19, no. 3: 349-362. http://www.editlib.org/p/30510.

Vajoczki, S., S. Watt, N. Marquis, M. Vine and R. Liao (2011), 'Students approach to learning and their use of lecture capture', Journal of Educational Multimedia and Hypermedia 20, no. 2: 195-214. https://www.learntechlib.org/primary/p/36105/.

Whatley, J., and A. Ahmad (2007), 'Using video to record summary lectures to aid students' revision', Interdisciplinary Journal of E-Learning and Learning Objects 3, no. 1: 185-196. https://www.learntechlib.org/p/44805/.

Wiese, C., and G. Newton (2013), 'Use of lecture capture in undergraduate biological science education', The Canadian Journal for the Scholarship of Teaching and Learning 4, no. 2: 1-24. http://dx.doi.org/10.5206/cjsotl-rcacea.2013.2.4.

Zhang, D., L. Zhou, R. Briggs and J. Nunamaker Jr. (2006), 'Instructional video in e-learning: Assessing the impact of interactive video on learning effectiveness', Information and Management 43: 15-27. https://doi.org/10.1016/j.im.2005.01.004. 